\title{
Subject Index
}

Actants 297

Aesthetic(s) 19, 24, 94, 105-106, 157, 215, 265, 276

Aleppo Codex 69, 74, 79, 81-82, 86-88, 99-100, 102

Annotation(s) 5, 39, 49, 51-60, 113-114, $128,133,136,140-141,143,146,149$, 222-223, 229, 238, 241

Apocryphal Acts 44

App(s) 23, 247, 250, 252, 255-260, 275, 286-287, 300-301

Arabic 7, 36, 48, 52-53, 60, 68-70, 72-73, 75-77, 82-84, 88, 127, 175, 183, 200, 215, 217, 219, 222-227, 230, 231, 236-237, 240, 242-244, 263-264, 266, 270, 275-277, 280

Art/artistic 21, 51-52, 54, 56-58, 105-106, 115-117, 135-136, 154-155, 157, 161, 163, $165,168,170,175,178,181,251,264$, 283-284, 285

Ashkenaz/Ashkenazi 94,110-111,114, 116 Authority 4, 8, 31, 63, 156, 162-164, 185-186, $253,257,261,263,275,277,279$

Book history 2, 265

Book(s) of Hours 120, 126, 129, 146, 161

Burning (books) 24, 289-291, 294

Cairo Codex 71-72, 74, 80-81, 86

Canon(ical) 7, 13, 24, 35-36, 38-44, 46-49, 52, 60, 134, 183, 209, 217, 244, 252-253, 260, 283

Christ, see "Jesus"

Codex/codices $1,3,6,8-9,15,35,38,41$, 47-48, 51-52, 60, 63, 66-83, 85-88, 91-95, 97-107, 109-117, 184, 187, 217-218, 220-222, 233, 243-244, 250, 252, 254, 281, 296-297

Codex Sinaiticus 35, 38, 48, 254

Codicology/codicological 40,53,55, 60, 70-71, 73, 76, 87, 92-94, 116, 204, 217, 220, 222, 242

Coding/encoding 7,169, 188-190, 199, 202, 213-214, 223, 225, 232-233, 235-238, 241, 276-277
Column(s) 15-16, 18-20, 26-29, 37, 45, 77-79, 95, 102-106, 109, 113-114, 123, 131, 133, 145-146, 204, 221

Dead Sea Scrolls 5, 13-33, 36, 63, 65, 71, 75, $91,102,114,120-121$

Desecration 9, 284, 289-290, 294, 301

Device(s) 1, 247, 250, 252-253, 255-259, 263, 270-276, 281, 286, 301

Diacritic(s) 214, 222-225, 228, 230-231, 233-237, 240, 242-243, 275-276

Didache 44

Digitised/digitisation 110, 116, 184, 190, 219, 253-254, 265-266, 271-273, 275-276, $281,287,301$

Electronic 8, 140, 150, 203-204, 216, 233 , 242, 244-245, 247, 252, 254, 261, 263, 265-266, 270-276, 279, 286, 289, 295

Ethnography/ethnographic 8, 162, 177, 263, 270, 274, 282, 298

Fragment(s) 5, 14-15, 18-20, 26-30, 36, 43-44, 49, 51-55, 57-59, 61, 67, 71-72, 74-75, 77, 81, 83, 88-89, 91, 93, 102, 217, 224-225, 229, 231, 275

Function/functionality $6,8,92,182$, 204-205, 238-239, 251-252, 270, 279, 281-283, 285, 294

Gender 7-8, 153, 263, 292

Genizah 6, 63, 67, 71-89, 91-93, 102, $116-117,218,222,243$

Gloss(es) 35-36, 60, 101, 110, 116-117, 119 , 131-132, 142, 150, 222, 245

Gospel of Thomas 35, 38-39, 42

Greek 36-38, 44, 70, 73, 93, 134, 183, 186-189, 192-193, 195, 197-203, 219-221, 249

Gutenberg (press) 132, 143, 149, 213-214, 232

Hebrew $6,13,15,18,24,26-27,32,36$, 63-66, 68-73, 75-79, 81-83, 85, 87-89, 91-95, 97-103, 105, 110-121,

Ә Open Access. (c) 2020 Bradford A. Anderson, published by De Gruyter. (œ) BY-NC-ND This work is licensed under a Creative Commons Attribution-NonCommercial-NoDerivatives 4.0 International License.

https://doi.org/10.1515/9783110634440-015 
125, 131, 134, 136, 143-144, 171, $174-175,183,186,188,210$

Iconic/iconicity 2, 8-10, 153, 156, 161, 177, 283-285, 289, 292-298, 300-301

Illuminated/illumination 72, 105, 119 , 143-144, 153-154, 157, 161-162, 165 , $170,175,177$

Incipit(s) 122, 125-126, 128-129, 131, 133-136, 138-139, 142-149, 229

Ink $3,15,57,119,125,128,143,148,155,219$, $225,227,231,270$

Jesus, Christ 121, 131, 141, 174, 187, 192, 198, 249-250

Josephus 46, 64, 85

Journalling, Bible 153-178

Karaite, see "Qaraite"

Layout 5-6, 8, 13-33, 68, 91, 93-107, 109-116, 119-129, 131-137, 139, 141, 143, 147-148, 162, 165, 173-174, 192, 217, 221-222, 229, 233, 241, 249-250, 252-253

Latin $37-38,121,126-129,131-132$, 134-136, 138-139, 142-149, 186, 188, 193-194, 197-201, 220-221

Leningrad Codex $66,72,74,79,86,88$, 99-100, 102

Liminal/liminality 1, 3, 10, 294-295

Liturgy/liturgical 6,13,16, 39, 64-65, 70-71, 73-74, 79-87, 92-93, 101-102, $115,120-122,124-129,132-133,136$, 138-139, 141, 143, 145-151, 220-221, 247-248, 262, 296

Maimonides $65-69,79,81,84,87-88$, 97-100, 103, 105-110, 112-114, 117

Manuscript(s) 1-2, 5, 7, 10, 13-15, 18, 21-24, 27, 30-31, 35-43, 47-49, 51-54, 58-61, 63-64, 6667, 70-72, 74-80, $82,85,87-88,91-92,94,98-100,102$, 105, 107, 109-117, 119-122, 124-129, 130-133, 137-138, 147, 150-151, 162, 165, 181-185, 187-207, 209-211,
213-217, 219, 221-225, 227-245, 249, 253-254, 265, 280-281, 294, 297-299

Markup 7, 213-214, 223, 231, 233-240, 242, 244-245

Moses $64-65,68-69,71-72,80,84,87$, 96-100, 103-104, 113, 168

Muhammad 7, 181, 196-202, 198, 218, 228, 264

muṣḥaf/mașāḥif 70, 72, 83, 85, 217-218, 220, 228, 242-244, 263-264, 266-270, 272-278, 280

Oecumenius 183, 187, 190, 192-193, 197, 210

Orthography/orthographic 224, 237, 244, $271,275,277-279$

Palaeography $21,30,40$

Palimpsest 52-54, 59-61, 219, 228, 233, 243,245

Paper 3, 75-78, 83, 88, 136, 141, 143, 148, 154-157, 160, 164, 174, 185, 217, 219-220, 263, 266-267, 270, 274, 279

Papyrus/papyri 5, 35-49, 73, 187, 211, 217-220, 224, 243-245

Paratext(s)/paratextual 3-5, 7-10, 35, 37, 39-44, 46, 182-183, 190, 192, 195, 204-205, 233, 241, 247-255, 257-262

Parchment 14, 55-59, 64, 66-67, 76-78, 80, 102, 122, 217-222, 224, 244

Performance/performative/performativity 2 , 6, 9, 119-120, 122, 124-127, 129, 133-134, 136, 141-143, 145-149, 164, 283-285

Pentateuch $64,66-67,95-97,103,110$, 112-113, 115-116, 133

Poem/ Poetry/ Poetic 5, 13, 16-18, 22, 24-25, 27, 29-33, 66, 73, 76-77, 86, 95-100, 103-111, 113-114, 119-120, 122,163

Print/ printing press $1,3,5-6,8,51,70$, 87, 119-121, 123, 132-133, 135-141, 143-151, 153-155, 158, 161-164, 168-170, 175-177, 181-182, 184-185, 190, 192, 203-206, 210, 213-216, 232, 245, 247-258, 260-262, 264-267, 270, 275-281, 287-288, 297-298 
Prose 16-22, 24-27, 31, 119

Protoevangelium of James 44

Purity (ritual) $8,73,264,267-269,273-274$

Qaraite/Qaraism 8, 63, 67, 80-86, 89, 91

Qumran 8, 15, 18, 22, 23, 25-28, 30, 32-33, $36,63-64,87,91$

Rabbinic/Rabbanite 6,63-64, 68-70,73, $75,80-86,92,94,288$

Rashi 71, 95, 110

Reception (history) 1, 7, 9-10, 13-16, 31, 35, 48, 119-120, 128, 136, 140, 158, 162, $165,177,183-185,190,192,202-205$, 209, 248

Ritual 8, 85, 92, 218, 264, 269, 273, 283-285, 289-290, 295-298, 300-301

Roll(s), see "scroll(s)"

Sefer $6,67-69,81,83,112$

Sefer Torah 6, 63-68, 85, 88, 98, 113

Sepharad/Sephardic 94, 97-98, 100, 106, 111-112, 116

Scribe(s)/scribal 6-7, 14-19, 22-24, 27-28, 31-33, 36, 38-39, 41-42, 45-49, 51, 53-60, 66-67, 69-70, 75, 77-78, 86-88, 91, 94, 97, 100-103, 105, 108-116, 122, 127-128, 148, 153, 161-162, 186-187, 190, 192, 195, 199, 201-202, 213, 221, 223, 229, 233

Script 7, 13-15, 41, 54-57, 83, 94, 119, 123, 200, 215-216, 219, 222-225, 228, 230-231, 237, 241-244, 264-265, 270, 275-277, 280

Scroll(s) (roll[s]) 1, 3, 5-6, 9, 13-33, 36, 39, 63-71, 73-75, 77, 79, 81, 83-88, 91-95, 97-99, 101-103, 110-117, 120-121, 184, 217, 220-221, 249, 281, 290, 294, 297, 299-301

Shepherd of Hermas 44

Social media 8, 153-154, 260

Subtitle(s), see "Title(s)"

Superscription(s) 16, 26, 121, 125, 127, 129, 131-133, 136, 141, 143-146
Synagogue $63-65,67,71,73,78-79,82$, 84-85, 92, 101, 115, 294, 299

Talmud $64-66,71,73-75,84-85$, 93-98, 100-103, 109-110, 116-117, 286-287, 301

Targum 77, 110

Technology(ies)/technological 1, 3, 8, 10, $70,74,76,86,132-133,140,150,177$, 181, 213-218, 232-233, 239, 241-245, 247-251, 253, 256, 260-263, 265-266, 269-270, 272-273, 275, 277-282, 285, 287-288, 296, 299, 301

Title(s)/subtitle 5, 35-37, 41, 45, 78, 121, 123, 131, 134-136, 139, 141-143, 145-146, 183, 194, 204, 248, 252-253, 257, 260

Torah 6, 23-25, 36, 49, 63-71, 74-75, 78-81, 83-85, 87-89, 94, 98-104, 112-116, 175, 289-290, 294

Torah Scroll 6, 63-67, 69-71, 79, 81, 83-85, 94, 98-99, 101-103, 112-116, 290

Transmission 1, 3-7, 9-10, 35, 40, 51-53, 60-61, 63, 69, 77, 86, 94, 182-183, 202-203, 216-217, 221-222, 228, 239, 249, 254, 270, 277, 281

Translation $3,6,16,31,53,55,72,77,78$, 120, 125-127, 129, 131, 134, 145-148, $168,175,253,258-259,271,275,286$, 296, 298

Tyndale, William 132-133, 147, 151 Typography/typographic(al) 6, 93, 136, 145, 153, 159, 181-182, 184, 201, 214, 249 , 253, 275-276, 278

Vacat 18, 27, 29

Vulgate $119,122,125,134,136,139$

Wyclif(fe), John/Wycliffite Bible 120, 126, 127-134, 136, 138, 142, 147-151

YouVersion 7, 247, 252-253, 255-258, 260, 286 
